\title{
How to Write a Good Paper in Computer Science and How Will It Be Measured by ISI Web of Knowledge
}

\author{
R. Andonie, I. Dzitac
}

\author{
Răzvan Andonie \\ Department of Computer Science \\ Central Washington University, USA \\ and \\ Department of Electronics and Computers \\ Transylvania University of Braşov, Romania \\ E-mail: andonie@cwu.edu
}

\author{
Ioan Dzitac \\ Department of Mathematics-Informatics \\ Aurel Vlaicu University of Arad \\ 310330 Arad, Romania \\ and \\ Cercetare Dezvoltare Agora \\ Piatţa Tineretului, 8, Oradea, Romania \\ Email: ioan.dzitac@uav.ro
}

\begin{abstract}
The academic world has come to place enormous weight on bibliometric measures to assess the value of scientific publications. Our paper has two major goals. First, we discuss the limits of numerical assessment tools as applied to computer science publications. Second, we give guidelines on how to write a good paper, where to submit the manuscript, and how to deal with the reviewing process. We report our experience as editors of International Journal of Computers Communications \& Control (IJCCC). We analyze two important aspects of publishing: plagiarism and peer reviewing. As an example, we discuss the promotion assessment criteria used in the Romanian academic system. We express openly our concerns about how our work is evaluated, especially by the existent bibliometric products. Our conclusion is that we should combine bibliometric measures with human interpretation.

Keywords: scientific publication, publication assessment, plagiarism, reviewing, bibliometric indices.
\end{abstract}

\section{Introduction}

Faculty work generally falls into three categories: research, teaching, and service. Assessment protocols have considered, to a varied extent, scholarly activities performed in each of these areas. Faculty assessment is conducted for purposes of reappointment, promotion, the awarding of tenure, and professional development.

During the last decades, a societal focus on the work of university faculty as a measure of return on the public's investment in higher education stimulated a reevaluation of how faculty performance ought to be measured and assessed. The development of workable assessment systems is difficult largely due to the fact that the value of assessment is often controversial:

- Assessment methods are defined differently from discipline to discipline.

- Assessment methods depend on the communication of standards upon which judgments of quality will be based and acceptable mechanisms for documenting faculty work.

- As members of a profession, faculty reserve the right to be the sole judges of the quality of the work performance of those claiming membership among their ranks.

At different levels, non-faculty administrators are also involved in the assessment process of faculty. There are cases when non-faculty are judging the scientific activity of faculty solely based on criteria like number of publications and impact factors, without having the expertise to pertinently judge these publications.

This creates a possible conflict and, in many cases, we can observe tensions in the faculty-administrator relationship [1]. The conflict starts from a communication failure between the two groups. Basically, 
faculty and administrators, share the same goals. Beside the psychological aspect (faculty do not like to be judged by non-academics), another cause of tension is the difficult question "How do we measure academic performance?"

Research performance is typically measured in terms of productivity, relying largely on the use of quantitative measures such as the number of publications, value of grants, or other creative works produced over a specified period of time. Many universities use indexing systems, like Thompson Scientific, as a main assessment tool for publications. But how much can we trust such a numerical criterion? Is it enough to count the number of citations of your paper to judge its value?

Our paper has two major goals. First, we focus on assessment techniques for scientific publications. We discuss the limits of numerical assessment tools. We particularly analyze the specific aspects of computer science (CS) publications knowing that cross-disciplinary comparisons should be generally avoided.

Second, we give guidelines on how to write a good paper, where to submit the manuscript, and how to deal with the reviewing process. We report our experience as editors of IJCCC. From this perspective, we also analyze two important aspects of publishing: plagiarism and peer reviewing.

We illustrate with the promotion assessment criteria used in the Romanian academic system. Finally, we discuss the "publish or perish practice" from the perspective of the current publication assessment techniques.

\section{Assessment of CS scientific publications}

Books, which some disciplines do not consider important scientific contributions, can be a primary vehicle in CS. We discuss here only dissemination of scientific results by conference proceedings and journals and we start with an important statement: The order in which a CS publication lists authors is generally not significant. In the absence of specific indications, it should not serve as a factor in researcher evaluation.

In the CS publication culture, prestigious conferences are a favorite tool for presenting original research, unlike disciplines where the prestige goes to journals and conferences are for raw initial results. Acceptance rates at very selective CS conferences are between $13 \%$ and 20\%. Can we tell from the acceptance rate alone how good a conference is? The answer is negative. For example, the International Joint Conference on Neural Networks (IJCNN) is a much better conference than shown by its 2008 acceptance rate, which was $58 \%$. As a regular reviewer of IJCNN, one of the authors of this paper (R.A.) considers that about $80 \%$ of the submitted papers are at least acceptable. We cannot tell how selective a conference (or a journal) is only by the percentage of papers it accepts because far fewer bad papers are submitted to the best conferences and journals.

CS journals have their role, often to publish deeper versions of papers already presented at conferences. While many researchers use this opportunity, others have a successful career based largely on conference papers.

There is an increasing tendency to numerically measure the quality of a paper. The starting point would be data from citation databases, such as Institute for Scientific Information's Web of Science, that can be analyzed to determine the popularity and impact of specific articles, authors, and publications. In ISI Web of Science citation metrics information is available only when records on the publication list have been added from the Web of Science. Usually metrics are "Sum of the Times Cited", "Average Citations per Item" and "h-index". According to Hirsch [2], $h$ is the number of articles greater than $h$ that have at least $\mathrm{h}$ citations. An h-index of 20 means that there are 20 items that have 20 citations or more. The accuracy of these metrics largely depend on the accuracy of the ISI database.

The Journal Citation Reports (JCR), published annually by Thomson Reuters, provides quantitative tools for ranking journals in accordance to statistical information from citation data. Ranking is performed, for instance, by the impact factor, which is a measure of the frequency with which the "average 
article" in a journal has been cited in a particular year or period. The annual JCR impact factor is a ratio between citations and recent citable items published. Only citations from papers indexed by ISI Web of Science are considered.

Thus, the impact factor of a journal is calculated by dividing the number of current year citations to the source items published in that journal during the previous two years. The impact factor $\operatorname{JCR}(J, Y)$ of journal $J$ in year $Y$, is

$$
c(Y ; Y-2, Y-1) / p(Y-2, Y-1),
$$

where $p(Y-2, Y-1)$ is the number of articles published in journal $J$ in the previous two years $(Y-1$ and $Y-2)$, and $c(Y ; Y-2, Y-1)$ is the number of citations in year $Y$ of papers published during the previous two years in journal $J$.

Publication quality is just one aspect of research quality, impact is one aspect of publication quality, and the number of citations is one aspect of impact. Citation counts rely on databases such as ISI, CiteSeer, ACM Digital Library, Scopus, and Google Scholar. They, too, have limitations. An issue of concern to computer scientists is the tendency to use publication databases that do not adequately cover CS, such as Thomson Scientific's ISI Web of Science. The principal problem is what ISI counts [3]. The results make Niklaus Wirth, Turing Award winner, appear for minor papers from indexed publications, not his seminal 1970 Pascal report. As another example, Knuth's milestone book series does not even figure. Other evidences of ISI's shortcomings for CS are [3]:

- ISI's internal coverage (i.e., percentage of citations of a publication in the same database) is over $80 \%$ for physics or chemistry, but only $38 \%$ for CS. Therefore, we should not make crossdisciplinary comparisons based on number of citations.

- ISI does not index many top conferences (for instance, The International Conference on Software Engineering (ICSE), the top conference in the field) but indexes SIGPLAN Notices, an unrefereed publication.

- ISI's "highly cited researchers" list includes many prestigious computer scientists but leaves out such iconic names as Wirth, Parnas, Knuth and all the ten 2000-2006 Turing Award winners except one.

- Any evaluation criterion, especially quantitative, must be based on clear, published criteria. The methods by which ISI selects documents and citations are not published or subject to debate.

The problem for computer scientists is that assessment relies on often inappropriate and occasionally outlandish criteria. Evaluation criteria, like ISI's impact factor or conference acceptance rates are flawed. Assessment criteria must themselves undergo assessment and revision. We should at least try to base it on metrics acceptable to the profession [3]: "Publication counts only assess activity. Giving them any other value encourages "write-only" journals, speakers-only conferences, and Stakhanovist research profiles favoring quantity over quality."

\section{Where to publish your work: conference vs journal}

The first thing to start your research is to know what the major journals and conferences in that field are. The rule of thumb is to read "good" papers and submit your papers to "good places". How to recognize a good journal or conference? It is quite easy if you already went through the reviewing process of that publication: a good journal/conference tends to have rigorous review process. If you are a graduate student, work with your mentors to understand what constitutes good versus bad conference/journal. 
When ranking conferences, you should look at the following factors: acceptance rate, review process, program committee, who the publisher of the proceedings is, and which database is indexing the published proceedings.

This is an example of a good conference (see T. N. Vijaykumar [14]):

The ACM/IEEE International Symposium on Computer Architecture (ISCA) is the top forum for architecture and has been so since 1975. ISCA papers are 10-12 pages in length with detailed results, and go through around 5-6 double-blind reviews by the top experts on the topic. The acceptance rate is $15-20 \%$, decided by a National Science Foundation (NSF) - panel-style, 20-person program committee. ISCA takes only 30-35 papers a year (there are no short papers, no posters).

For ranking journals, we have to look at the JCR impact factor, publishing house, and editors. The ISI ranking system is based on the JCR impact factor (see Fig. 1).

\begin{tabular}{|c|c|c|c|c|c|c|c|c|c|c|c|}
\hline \multicolumn{2}{|c|}{ UPDATE MAAKED UST } & \multicolumn{10}{|c|}{ Ranking is based on your journal and sort selections. } \\
\hline \multirow[b]{2}{*}{ Mark } & \multirow[b]{2}{*}{ Rank } & \multirow[b]{2}{*}{$\begin{array}{l}\text { Abbreviated Journal Title } \\
\text { (linked to jourmal information) }\end{array}$} & \multirow[b]{2}{*}{ ISSN } & \multicolumn{6}{|c|}{ JCR Data i } & \multicolumn{2}{|c|}{ Eigenfactor ${ }^{\mathrm{TM}}$ Metrics i) } \\
\hline & & & & Total Cites & $\begin{array}{l}\text { Impact } \\
\text { Factor }\end{array}$ & $\begin{array}{l}\text { 5-Year } \\
\text { Impact } \\
\text { Factor }\end{array}$ & $\begin{array}{c}\text { Immediacy } \\
\text { Index }\end{array}$ & Articles & $\begin{array}{c}\text { Cited } \\
\text { Half-life }\end{array}$ & $\begin{array}{l}\text { Eigenfactor TM } \\
\text { Score }\end{array}$ & $\begin{array}{l}\text { Article Influence } \\
\text { Score }\end{array}$ \\
\hline$\square$ & 41 & ASIAN J CONTROL & $1561-8625$ & 359 & 0.600 & 0.686 & 0.237 & 76 & 4.7 & 0.00093 & 0.156 \\
\hline$\square$ & 42 & ASSEMBLY AUTOM & 0144-5154 & 212 & 0.562 & 0.526 & 0.075 & 40 & 5.4 & 0.00058 & 0.130 \\
\hline$\square$ & 43 & IMA J MATH CONTROLI & 0265-0754 & 324 & 0.535 & & 0.037 & 27 & 8.6 & 0.00101 & \\
\hline$\square$ & 44 & INF TECHNOL CONTROL & $1392-124 x$ & 54 & 0.495 & & 0.054 & 37 & & 0.00018 & \\
\hline$\square$ & 45 & PI MECH ENG I-] SYS & $0959-6518$ & 247 & 0.447 & 0,414 & 0.033 & 90 & 5.6 & 0.00079 & 0.120 \\
\hline$\square$ & 46 & MODEL IDENT CONTROL & $0332-7353$ & 110 & 0.435 & 0.648 & 0.000 & 6 & 7.9 & 0.00030 & 0.270 \\
\hline$\square$ & 47 & AT-AUTOM & 0178-2312 & 176 & 0.378 & & 0.050 & 60 & 5.3 & \begin{tabular}{l|l}
0.00017 \\
\end{tabular} & \\
\hline$\square$ & 47 & CONTROL CYBERN & 0324-8569 & 415 & 0.378 & 0.560 & 0.000 & 14 & 9.0 & 0.00128 & 0.256 \\
\hline$\square$ & 49 & JDYN CONTROL SYST & 1079-2724 & 201 & 0.377 & 0.565 & 0.080 & 25 & 7.3 & 0.00083 & 0.304 \\
\hline$\square$ & 50 & INT 3 COMPUT COMMUN & 1841-9836 & 95 & 0.373 & & 0.205 & 39 & & 0.00011 & \\
\hline$\square$ & 51 & INTELL AUTOM SOFT CO & 1079-8587 & 102 & 0.349 & 0.301 & 0.136 & 44 & 6.2 & 0.00019 & 0.061 \\
\hline$\square$ & 52 & I I MEAS CONTROL & 0142-3312 & 194 & 0.340 & 0.586 & 0.000 & 29 & 6.8 & 0.00052 & 0.194 \\
\hline$\square$ & 53 & INT J ROBOT AUTOM & 0826-8185 & 144 & 0.339 & 0.438 & 0.029 & 35 & 7.1 & 0.00041 & 0.133 \\
\hline$\square$ & 54 & MEAS CONTROL-UK & $0020-2940$ & 168 & 0.329 & 0.392 & 0.029 & 34 & 6.7 & 0.00039 & 0.100 \\
\hline$\square$ & 55 & REV IBEROAM AUTOM IN & $1697-7912$ & 25 & 0.291 & & 0.026 & 39 & & 0.00012 & \\
\hline$\square$ & 56 & JYST ENG ELECTRON & $1004-4132$ & 195 & 0.269 & & 0.000 & 196 & 3.1 & 0.00038 & \\
\hline$\square$ & 57 & AUTOMAT REM CONTR + & 0005-1179 & 984 & 0.251 & 0.238 & 0.121 & 165 & $>10.0$ & 0.00205 & 0.118 \\
\hline$\square$ & 58 & COMPUT CONTROL ENG & 0956-3385 & 177 & 0.158 & 0.325 & & 0 & $>10.0$ & 0.00025 & 0.078 \\
\hline$\square$ & 59 & CONTROL ENG & $0010-8049$ & 92 & 0.024 & 0.038 & 0.042 & 95 & & 0.00024 & 0.021 \\
\hline
\end{tabular}

Figure 1: ISI Journal Ranking: IJCCC has impact factor 0.373.

For example, let us compute the IJCCC JCR 2009 impact factor. We have: 34 items published in IJCCC (in 4 regular issues) in 2007; 35+ $89=124$ items published in IJCCC (in 4 regular issues +1 supplementary issue) in 2008. The total number of articles published in 2007 and 2008 in IJCCC is $p(2007,2008)=34+124=158$. In 2009, there are $c(2009 ; 2007,2008)=22+37=59$ citations to items published in 2007 and 2008. Hence, $J C R(I J C C C, 2009)=c(2009 ; 2007,2008) / p(2007,2008)=$ $59 / 15^{8}=0.373$.

IJCCC is a new journal, founded in 2006. Authors use different journal title abbreviations, and this makes journal identification by ISI problematic. In addition to this, since the supplementary 2008 issue contains the ICCCC 2008 proceedings, many citations appear as "Proceedings of ICCCC 2008", without mentioning the journal. These are two reasons why the ISI Web of Science database contains incorrect IJCCC entries, which influences the impact factor of our journal. We recognize here the traditional "garbage in - garbage out" problem.

A solution would be to use for each journal its unique ISSN. This is certainly not very easy, because all indexing systems have to change, and authors may have to include the ISSN's in their list of publications. However, we think that the effort is worth, since this would make bibliometric indicators more precise. 
Here are examples of important journals and conferences, for different CS domains:

- Database: IEEE Trans on Knowledge and Data Engineering, ACM Trans on Database Systems, Int'l Conf on VLDB.

- Software Engineering: IEEE Trans on Software Engineering, ACM Trans on Software Eng. and Methodology, IEEE Int'l Conf on Software Engineering.

- Computer Networks: IEEE/ACM Trans on Networking, IEEE INFOCOM, ACM Mobicom.

- Parallel/Distributed Systems: IEEE Trans on Parallel and Distributed Systems, ACM Trans on Computer Systems, ICDCS, IPDPS.

- Neural Networks: IEEE Trans. on Neural Networks, Neural Computation, NIPS, IJCNN, ICANN, IWANN, ESANN.

Should we submit to a journal or conference? In the CS context, this question deserves a discussion.

\subsection{Why prefer a conference}

According to Patterson et al. [4], in CS, conference publication is preferred to journal publication, at least for experimentalists. This was the recommendation (a memo) of the Computer Research Association (CRA) in 1999. The CRA memo asserts that conference publication is superior to journal publication in computer science. According to the memo, the typical conference submission receives four to five evaluations, whereas the typical journal submission receives only two to three evaluations.

Computing researchers are right to view conferences as an important archival venue and use acceptance rate as an indicator of future impact. Papers in highly selective conferences, with acceptance rates of $30 \%$ or less, should continue to be treated as first-class research contributions with impact comparable to, or better than, journal papers [5]. This distinguishes computer science from other academic fields where only journal publication carries real weight. There are two main reasons to publish in the proceedings of selective conferences:

- Conferences are more timely than journals.

- Conferences have higher standards of novelty. Journals often only require $20-30 \%$ of the material to be new, compared to an earlier conference version.

Conference selectivity serves two purposes: pick the best submitted papers and signal prospective authors and readers about conference quality. Is there a connection between conference acceptance rate and impact factor, where impact is measured by the number of citations received? The answer is positive, up to some threshold. Adopting the right selectivity level helps attract better submissions and more citations. Chen and Konstan [5] found, with respect to ACM-wide data, that acceptance rates of $15-20 \%$ seem optimal for generating the highest number of future citations for both the proceedings as a whole and the top papers submitted. Conferences rejecting $85 \%$ or more of their submissions risk discouraging overall submissions and inadvertently filtering out high-impact research.

\subsection{Why prefer a journal}

Many universities evaluate faculty on the basis of journal publications because, in most scientific fields, journals have higher standards than conferences. Journals may have longer page limits and journal reviews tend to be more detailed. Many times, conference committees enlist inexperienced graduate students as reviewers of papers in order to meet the quota for reviews. Because conference papers are 
limited in length, and because a large number of papers must be reviewed within a short time, the quality of reviews of conference papers is generally low. In contrast, for journals, because there are usually no page limits, authors can explain their ideas completely. Editors can choose qualified reviewers carefully. Reviewers can take adequate time to write thorough reviews.

By polishing a manuscript for journal publication, the author minimizes the number of errors and improves the clarity of the exposition. Thus, journal papers are more likely to be correct and readable than conference papers. Journals are more widely distributed through libraries than conference proceedings, which go out of print quickly. In all disciplines, the criteria for quality include innovation, thoroughness, and clarity, appraised through rigorous peer review. Across disciplines, there are common standards for the evaluation and documentation of publicly presented scholarly work [6]. According to some authors, computer science is not sufficiently different from other engineering disciplines to warrant evaluation on completely different grounds. The evaluation of the scholarship of academic computer scientists should continue to emphasize publications in rigorously refereed, archival scientific journals.

The "conferences vs journal" debate is far from over and was recently relaunched in Communications of the ACM. Studying the metadata of the ACM Digital Library, Chen and Konstan [5] found that papers in low-acceptance-rate conferences have higher impact than in high-acceptance-rate conferences within ACM. Highly selective conferences - those that accept $30 \%$ or less of submissions - are cited at a rate comparable to or greater than ACM jounals.

According to Vardi [7], unlike every other academic field, computer science uses conferences rather than journals as the main publication venue. This has led to a great growth in the number of low level conferences. Some call such conferences "refereed conferences" but we all know this is just an attempt to mollify promotion and tenure committees. The reviewing process performed by program committees is done under extreme time and workload pressures, and it does not rise to the level of careful refereeing. Only a small fraction of conference papers are followed up by journal papers.

\section{How to write a good paper and how to deal with the editor}

Ask two questions before starting: i) What is new in your work?, and ii) What are you going to write? Emphasize on the originality and significance of your work. Organize your thinking and decide the structure (outlines) of your paper. Stick on your central points throughout the whole paper and remove all unnecessary discussions. There are many good papers on "How to write a good paper", and one of the best known was authored by Robert Day [8]. One could find there some general guidelines which always help:

- Start writing the day you start the research and maintain a good bibliographic database (use BibTeX and LaTeX).

- Think about where to submit early.

- Don't try and prove you are smart and avoid the kitchen sink syndrome.

- Start from an outline.

- Work towards making your paper a pleasure for the reviewer to read.

- Obey the guide to authors.

The structure of a CS paper is not different than the structure of any scientific publication: Title, Abstract, Introduction, Background, Related Work, System Model \& Problem Statement, Methods / Solutions, Simulations / Experiments, Conclusion, Acknowledgment, and References. Almost everybody knows this. However, there are some simple rules of thumb which can make life easier. 
According to the "Hourglass Model" [9], a paper should start from general, and go through particular back to general (Fig. 2).

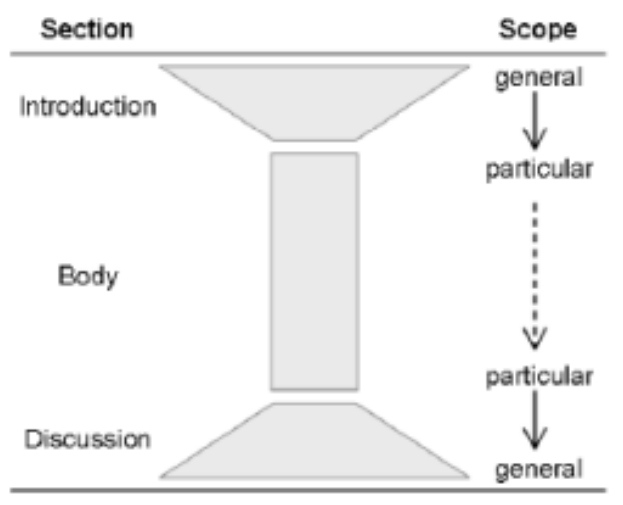

Figure 2: Hourglass Model (Swales [9]).

1. Choose a right title. The title should be very specific, not too broad. The title should be substantially different from others. Avoid general titles, e.g., "Research on data mining", "Contributions to Information Theory", "Some research on job assignment in cluster computing", or "A new framework for distributed computing".

2. Write a concise abstract. An abstract should tell:

- Motivation: Why do we care about the problem and the results?

- Problem statement: What problem is the paper trying to solve and what is the scope of the work?

- Approach: What was done to solve the problem?

- Results: What is the answer to the problem?

- Conclusions: What implications does the answer imply?

A good hint is pack each of these part into one sentence.

\section{Organization of your paper.}

- Plan your sections and subsections. Use a top-down writing method. Use a sentence to represent the points (paragraphs) in each subsections.

- Writing details: expand a sentence in the sketch into a paragraph.

- Keep a logical flow from section to section, paragraph to paragraph, and sentence to sentence.

4. Introduction: the most difficult part. This is why one of the authors of the present paper (R. A.) prefers to write the Introduction in the final stage and, whenever he writes a paper with students, he prefers to write this section entirely himself.

An Introduction should:

- Establish a territory:

- bring out the importance of the subject

- make general statements about the subject

- present an overview on current research on the subject 
- Establish a niche:

- oppose an existing assumption

- reveal a research gap

- formulate a research question

- continue a tradition, or propose a completely new approach

- Occupy the niche:

- sketch the intent of the own work

- outline important characteristics and results of your own work

- give a brief outlook on the structure of the paper

5. Related work and list of references. Use a proper selection of references. Show your knowledge in the related area. Give credit to other researchers (reviewers are usually chosen from the references). Cite good quality work, particularly when citing your own work, and up to date work. Related work should be organized to serve your topic. Emphasize on the significance and originality of your work.

6. Your conclusions. A research paper should be circular in arguments, i.e., the conclusion should return to the opening, and examine the original purpose in the light of the research presented.

Assuming that you have decided where to submit, and your paper is ready. What is the next step after writing a nice letter to the editor (if it is a journal) with your manuscript submitted electronically? Most probably, your paper will be rejected, or conditionally accepted after a major review. It is almost impossible to have your paper accepted without any modification suggested ( except if your name is Donald Knuth or David Patterson!). Even an acceptance "with minor modifications" is rare.

The best scientists get rejected and/or have to make major revisions. It is unreasonable to get defensive, unless it is really called for. You should address EVERY aspect of the reviewers concerns. Make it obvious to the reviewer through the Summary of Changes and the revised manuscript itself of the changes you have made. Do not add new science unless it is called for.

A good referee report is immensely valuable, even if it tears your paper apart. Remember, each report was prepared without charge by someone whose time you could not buy. All the errors found are things you can correct before publication. Appreciate referee reports, and make use of them. An author who feels insulted and ignores referee reports wastes an invaluable resource and the referees' time.

Finally, we have to remember what you put in the literature is your scientific legacy after all else is gone.

\section{Plagiarism and innovation}

Since IJCCC is a young journal, it is reasonable to believe that our review process is less professional than for a top ranked journal like IEEE Transactions, and our journal attracts many authors who are in their early research stages. Such authors are usually under terrible pressure to get something published or not to finish their $\mathrm{PhD}$, or not to be promoted (and possibly lose their jobs). The matter becomes serious for them, and some authors try everything to save their career, including plagiarism.

After receiving your paper, editors and reviewers have to deal with a very unpleasant task of which authors are probably not aware: they have to detect possible plagiarism. Only after your paper passes this preliminary screening it is considered for the true review. As IJCCC editors we have to reject about $8 \%$ because of detected plagiarism. Authors of these papers are blacklisted and not considered for future publication. We do not have any statistics about plagiarism frequencies at other publications, but this would certainly be of interest. We may even imagine a "plagiarism world map"! Therefore, we consider important to discuss plagiarism here. 
The rules of what constitutes plagiarism and how it should be dealt with are not always clear. According to the IEEE Institute print edition, there are five level of plagiarism:

"1. Uncredited verbatim copying of a full paper. Results in a violation notice in the later article's bibliographic record and a suspension of the offender's IEEE publication privileges for up to five years. 2. Uncredited verbatim copying of a large portion (up to half) of a paper. Results in a violation notice in the later article's bibliographic record and a suspension of publication privileges for up to five years. 3. Uncredited verbatim copying of individual elements such as sentences, paragraphs, or illustrations. May result in a violation notice in the later article's bibliographic record. In addition, a written apology must be submitted to the original creator to avoid suspension of publication privileges for up to three years. 4. Uncredited improper paraphrasing of pages or paragraphs (by changing a few words or phrases or rearranging the original sentence order). Calls for a written apology to avoid suspension of publication privileges and a possible violation notice in the later article's bibliographic record. 5. Credited verbatim copying of a major portion of a paper without clear delineation of who did or wrote what. Requires a written apology, and to avoid suspension, the document must be corrected."

The guidelines also make recommendations for dealing with repeated offenses.

According to the IJCCC Author Guidelines, submissions to IJCCC must represent original material:

"Papers are accepted for review with the understanding that the same work has been neither submitted to, nor published in, another journal or conference. If it is determined that a paper has already appeared in anything more than a conference proceeding, or appears in or will appear in any other publication before the editorial process at IJCCC is completed, the paper will be automatically rejected.

Papers previously published in conference proceedings, digests, preprints, or records are eligible for consideration provided that the papers have undergone substantial revision, and that the author informs the IJCCC editor at the time of submission.

Concurrent submission to IJCCC and other publications is viewed as a serious breach of ethics and, if detected, will result in immediate rejection of the submission.

If any portion of your submission has previously appeared in or will appear in a conference proceeding, you should notify us at the time of submitting, make sure that the submission references the conference publication, and supply a copy of the conference version(s) to our office. Please also provide a brief description of the differences between the submitted manuscript and the preliminary version(s).

Editors and reviewers are required to check the submitted manuscript to determine whether a sufficient amount of new material has been added to warrant publication in IJCCC. If you have used your own previously published material as a basis for a new submission, then you are required to cite the previous work(s) and clearly indicate how the new submission offers substantively novel or different contributions beyond those of the previously published work(s). Any manuscript not meeting these criteria will be rejected. Copies of any previously published work affiliated with the new submission must also be included as supportive documentation upon submission."

Whereas plagiarism can more or less measured and there are even software tools available which can help for this, the hardest part to judge as a reviewer is the level of innovation: How much innovation is enough to accept a paper?

According to Patterson et al. [4]: 
"When one discovers a fact about nature, it is a contribution per se, no matter how small. Since anyone can create something new (in a synthetic field), that alone does not establish a contribution. Rather, one must show that the creation is better. Accordingly, research in computer science and engineering is largely devoted to establishing the "better" property."

The degree of innovation required depends on the policy of the publication and how selective the conference/journal is. For example, let us illustrate with a good journal. The IEEE Transactions on Neural Networks is ranked 13th overall in terms of impact factor (2.62) among all electrical and electronic engineering journals (206 journals), according to the latest Journal Citation Report (see [10]). The average time between submission and publication (in print) is 18.8 months, which implies that the average time between final acceptance of a paper and publication is approximately 8 months. The conditions to have a paper accepted for IEEE Transactions on Neural Networks are posted in the authors guidelines:

- Full Papers are characterized by novel contributions of archival nature in developing theories and/or innovative applications of neural networks and learning systems. The contribution should not be of incremental nature, but must present a well-founded and conclusive treatment of a problem. Well organized survey of literature on topics of current interest may also be considered.

- Brief Papers report sufficiently interesting new theories and/or developments on previously published work in neural networks and related areas. The contribution should be conclusive and useful.

It is important to read very carefully these guidelines before submitting a paper. Words like "incremental" research are important and should be understood clearly. Editors, like accountants, are serious people and they do not play with words.

According to Qiu [11]:

"One-third of more than 6,000 surveyed across six top Chinese institutions admitted to plagiarism, falsification or fabrication. Many blamed the culture of jigong jinli - seeking quick success and short-term gain - as the top reason for such practices."

"Most academic evaluation in China - from staff employment and job promotion to funding allocation - is carried out by bureaucrats who are not experts in the field in question. When that happens, counting the number of publications, rather than assessing the quality of research, becomes the norm of evaluation."

"To critics such as Rao Yi, dean of the life-science school at Peking University in Beijing, the lack of severe sanctions for fraudsters, even in high-profile cases, also contributes to rampant academic fraud."

We discover the same situation in India [12]:

"The resulting push to publish, combined with ignorance about what exactly constitutes plagiarism and research misconduct, has led to a rise in such incidents in the last eight to 10 years."

"Meanwhile, the lack of both federal and institutional mechanisms that could detect and punish instances of misconduct have compounded the problem, say some scientists."

Actually, plagiarism appears in all countries, but it is more visible in countries: $i$ ) with high level of corruption, where plagiarism is not punished, $i i$ ) where only the number of papers is the measure of success, and iii) where plagiarism is not considered a major offense.

As editors and reviewers, we spend sometimes more time with detecting plagiarism than with judging the novelty of a paper. 


\section{The task of the reviewer}

There is an endless stream of research papers submitted to conferences, journals, and other periodicals. Many such publications use impartial, external experts to evaluate papers. This approach is called peer review, and the reviewers are called referees. Refereeing is a public service, one of the professional obligations of a computer science and engineering professional. Unfortunately, referees typically learn to produce referee reports without any formal instruction; they learn by practice [13]. The quality of a publication is also determined by the quality of the reviews. Good publications attract the best reviewers and keep this way, in a positive feedback, a high publication standard. For an acceptance rate of 33\%, it is fair to ask each published author to provide at least nine good reviews for submitted papers, assuming that each submitted paper has three reviewers.

Beside detecting plagiarism, editors have to face another administrative problem: they have to find good reviewers. Since IJCCC is less prestigious than an IEEE or ACM journal, it is perhaps less attractive for a good computer scientist to collaborate with us. As IJCCC editors, we have difficulties in motivating and recruiting good reviewers. The name of the editor can help. In our case, many of our international professional friends have accepted to write reviews simply because of our personal relationship. One rule we try to apply is to let all authors from Romania be reviewed by non-Romanian residents. The goal is to make our review process unbiased. The most reliable reviewers are experts in their postdoc stage. Senior computer scientists are less willing to meet the review deadlines. Our review process is blind, but not double-blind: reviewers do know the author's name. The simple blind review process is possibly more biased, but it has a big advantage: plagiarism is easier to detect.

Reading a paper as a referee is closer to what a teacher or professor does when grading a paper than what a scientist or engineer does when reading a published work. As a referee you must read the paper carefully and with an open mind, checking and evaluating the material with no presumption as to its quality or accuracy. If you want to be taken seriously as a referee, you must have a middle-of-the-road. A referee who always says "yes" or always says "no" is not helpful.

Don't waste that effort on a detailed critique of a badly flawed paper that can never be made publishable. Finding one or more fatal and uncorrectable flaws excuses the referee from checking all subsequent details. Your report should not be insulting. Don't refer to the author as "idiot" nor to the paper as "trash". Your review should be directed at the paper, not the author. In all cases, the evaluation should be objective and fair. The more psychologically acceptable the review, the more useful it will be.

After comparing the paper to an appropriate standard (not your own standards, which may be high or low), you should be able to put it into one of these categories:

(1) Major results; very significant (fewer than 1 percent of all papers). (2) Good, solid, interesting work; a definite contribution (fewer than 10 percent). (3) Minor, but positive, contribution to knowledge (perhaps 10-30 percent). (4) Elegant and technically correct but useless. This category includes sophisticated analyses of flying pigs. (5) Neither elegant nor useful, but not actually wrong. (6) Wrong and misleading. (7) So badly written that technical evaluation is impossible.

But what are the standards of a journal or conference? You should compare the paper with the average paper in that specific journal or conference, not with the best or worst. Of course, in some cases the average is too low and needs to be raised by critical refereeing.

As a reviewer, you should be alert to the author who tries to publish the same work in all its various combinations, permutations, and subsets, and to the author who adds the "least publishable unit" of new material to each paper. 


\section{Case study - the IJCCC reviewing process}

From the many hundreds of emails received by us from authors, we have selected some representative ones.

An "excuse letter" for detected plagiarism:

"Respected Sir,

I am Mrs. J. from ***. This paper was originally prepared in 2008 during my course work period as a conceptual paper. By the time I was not aware of the act of plagiarism. And this paper was submitted only by me without the knowledge of my supervisor. But, later in the middle of 2009 I came to know that preparing an article in this manner is avoided. Regarding this I sent a mail to the journal office stated that when can it be published. But I came to know that this paper has been sent for review process and you got the result as such.

So, I request you to forgive me for my activity which I have been done unknowingly and Now I know to prepare the articles which exhibit only my own findings and I am sure that hereafter this type of work will not be done by me.Once again I apologize for my action and Sorry for the inconvenience."

Here are four hilarious submission letters, with their typo and language errors:

"Dear Sir / Madam

This is two paper when you received my email just reply me.

**notes : which time i can recieved the final result.

Thank you very much"

"Hi,Dear professor i have send a new paper for your's journal

..., Msc. Faculty member and Head Research group"

"Dear Sir

Pl find my paper attched to this mail id. ..."

"Knowing the importance of your journal, we want to submit to you the advances of our research in the area in order to share them with your readers.

Hoping to hear from you soon"

Certainly, a nice submission letter is not a sufficient condition for a manuscript to be accepted. But can we expect a good paper from an author who does not know how to write a simple letter?

Here is a nice professional submission letter:

"Dear Dr. ...,

Please find attached our paper entitled .... This is joint work of .... I will serve as corresponding author. Please accept it as a candidate for the publication in IJCCC.

This manuscript is the authors' original work and has not been published nor has it been submitted simultaneously elsewhere. All authors have checked the manuscript and have agreed to the submission.

Thank you for your consideration.

Best regards,"

Finally, here is the first part of a good Summary of Changes document addressed to us after a major review: 
"Dear Editors:

I am the author of the paper entitled .... I revised my paper according to your suggestions and here is the explanation of the changes:

1. Section 1, paragraph 5, the first sentence is changed from "a fuzzy QoS routing protocol proposed to..." to "we present a Fuzzy controller based QoS Routing Algorithm...".

2. In Abstract, "NS2" is explained as network simulation version 2 explicitly.

...11. In Simulation section, the nodes are assigned classes randomly and we removed the class distribution item in Table 2 accordingly."

\section{Case study - promotion requirements in Romania}

In an effort to uniformly regulate promotion requirements in Romanian universities, the Romanian Ministry for Education [15] asks for a minimum number of published papers indexed by the ISI Web of Science citation system or other major citation indexing service. Under this relatively flexible umbrella, for each disciplines there are specific standards, in an attempt to automatize academic ranking. The ranking procedures are many times ambiguous and contradictory because of the possible exempts. Exempts are frequently modified, in accordance to the acting Minister of Education. For instance, one ISI indexed paper may be replaced by several papers indexed by other citation indexing services.

Everybody is asking for "ISI papers". Each year Thomson Reuters evaluates approximately 2,000 journals for possible coverage in Web of Science. ISI Web Of Science covers over 10,000 of the highest impact journals worldwide and over 110,000 conference proceedings. These are defined as ISI indexed papers. For CS, ISI indexed papers are the papers indexed by Science Citation Index Expanded. According to the present promotion regulations of the Romanian Ministry for Education, the required ISI indexed papers can be journal or conference papers. Among the many good publications covered by ISI Web of Science there also journals and proceedings of questionable quality.

Most promotion standards, including the basic criteria of the Romanian Ministry for Education, consider the number of ISI indexed papers, but not other publication assessment indicators, like impact factor and h-index. This Stakhanovist criterion favors quantity over quality. Physicists are sophisticated and they use more assessment indicators [16]: number of authors, number of citations, and impact factor. It is not easy to be a physicist in Romania, especially when you have to prepare your promotion portfolio. But, after all, let us mention that the author of the h-index is Jorge E. Hirsch, a physicist!

One may think that replacing the publication counter by the impact factor of the journal, or by the number of citations of the paper, would be sufficient to accurately quantify scholarship. At Thomson Reuters' web site [17], we find the following warning: "The impact factor should be used with informed peer review. In the case of academic evaluation for tenure it is sometimes inappropriate to use the impact of the source journal to estimate the expected frequency of a recently published article."

Using excessively the ISI indexing scheme to evaluate CS papers has additional drawbacks:

- As we have mentioned before, this creates from the very beginning a handicap for computer scientists since ISI does do not adequately cover CS.

- Another weakness of the ISI indexing scheme in CS is its poor coverage of high impact conferences, knowing that computer science uses conferences rather than journals as the main publication venue.

- A third weakness is the temptation to perform cross-disciplinary comparison.

Observation: One of the promotion requirements of the Romanian Ministry for Education is the publication of books as "first author". As we have mentioned before, the order in which a CS publication lists authors is generally not significant. For articles, these requirements do not refer to the order of authors. 


\section{Conclusions: The current publication and review model is killing re- search}

How efficient are bibliometric measures, like impact factor and h-index? The UK government is considering using bibliometrics in its Research Excellence Framework, a process which will assess the quality of the research output of UK universities and on the basis of the assessment results, allocate research funding. The bibliometric indicators of research quality were tested during 2009-09 [18]. The bibliometrics pilot exercise was conducted with 22 higher education institutions and covered 35 units of assessment from the 2008 Research Assessment Exercise. Both Thomson Reuters Web of Science and Elsevier's Scopus databases were used. The pilot exercise showed that citation information is not sufficiently robust to be used formulaically or as a primary indicator of quality; but there is considerable scope for it to inform and enhance the process of expert review.

According to [19], German universities distribute money to researchers by a formula that includes the Thomson impact factor. Each point of impact factor is worth about 1000 Euros. In Pakistan, researchers receive bonuses of up to US $\$ 20,000$ a year depending on the sum of the impact factors of the journals in which they publish. And the critique addressed to the Thomson impact factor, which is embedded in a commercial product, continues [19]:

"To an extent that no one could have anticipated, the academic world has come to place enormous weight on a single measure that is calculated privately by a corporation with no accountability, a measure that was never meant to carry such a load. Yes, some of us benefit from this flawed system-in addition to other rewards that come from publishing in high-impact journals, we collect nice cash bonuses. But none of this changes the fact that evaluating research by a single number is embarrassing reductionism, as if we were talking about figure skating rather than science."

Definitely, we have to express openly our concerns about how our work is evaluated, especially by commercial bibliometric products. Not only that these products are expensive, but their misuse reduces us to figures in different statistics and rankings.

While numeric criteria trigger strong reactions, peer review is strongly dependent on evaluators' choice and availability (the most competent are often the busiest), can be biased, and does not scale up. The solution is in combining techniques, subject to human interpretation. For instance, extract, first, a citation record for the individual candidate via one of the free Internet search engines (e.g., Google Scholar). Second, ask for evaluations concerning the significance of a candidate's work from carefully selected (i.e., impartial and highly qualified) scientific peers.

The pressure to publish is too large for most to ignore. Grants don't get funded unless we splatter our names across journals and conferences the world over. Grad students don't graduate. Assistants and adjuncts don't get tenure. Your CV is fewer than 5 pages? You must be stupid. Join more vacuous clubs, dues-hungry societies, and enter more regional poster conferences.

Too much time is spent writing papers rather than developing research. Too much time is spent calculating impact factors and finding out who is indexing what. Evaluation criteria, like ISI's impact factor or conference acceptance rates are flawed. The reviewing process is inherently flawed and may kill good papers. It is hard to find good reviewer, willing to do this voluntary work.

What is the solution? One option would be to slow down. Without the pressure to publish a number of ISI indexed papers each year, regardless where and how important they are, we might get thorough, lengthy, reproducible publications. Is this not what publishing is about? What do we gain from publishing incremental research papers? There are more people writing papers than people who have time to verify their results. 


\section{Bibliography}

[1] M. Del Favero and N. J. Bray, "Herding cats and big dogs: Tensions in the faculty-administrator relationship," in Higher Education: Handbook of Theory and Research, J. C. Smart, Ed. Springer, 2010, vol. 25, pp. 477-541. ISBN 978-90-481-8597-9 (print), 978-90-481-8598-6 (electronic), DOI: $10.1007 / 978-90-481-8598-6-13$.

[2] J. E. Hirsch, "An index to quantify an individual's scientific research output," Proceedings of the National Academy of Sciences of the United States of America, vol. 102, no. 46, pp. 16569-16572, November 2005. ISSN-0027-8424, DOI:10.1073/pnas.0507655102

[3] B. Meyer, C. Choppy, J. Staunstrup, and J. van Leeuwen, "Viewpoint research evaluation for computer science," Commun. ACM, vol. 52, no. 4, pp. 31-34, 2009, ISSN:0001-0782

[4] D. Patterson, L. Snyder, and J. Ullman, "Best practices Memo: Evaluating computer scientists and engineers for promotion and tenure," Computer Research Association, 1999.

[5] J. Chen and J. A. Konstan, "Conference paper selectivity and impact," Commun. ACM, vol. 53, no. 6, pp. 79-83, 2010, ISSN: 0001-0782

[6] C. E. Glassick, M. T. Huber, and G. I. Maeroff, Scholarship Assessed: Evaluation of the Professoriate. Jossey-Bass, 1997.

[7] M. Y. Vardi, "Conferences vs. journals in computing research," Commun. ACM, vol. 52, no. 5, pp. 5-5, 2009, ISSN: 0001-0782.

[8] R. A. Day, How To Write \& Publish a Scientific Paper. Oryx Press, 1998.

[9] J. Swales, Genre Analysis: English in Academic and Research Settings. Cambridge University Press, 1990, ISBN-10: 0521338131; ISBN-13: 978-0521338134.

[10] M. M. Polycarpou, "Editorial: A new era for the IEEE Transactions on Neural Networks," Neural Networks, IEEE Transactions on, vol. 19, no. 1, pp. 1-2, January 2008, ISSN 1045-9227.

[11] J. Qiu, "Publish or perish in China," Nature, vol. 463, pp. 142-143, 2010, ISSN: 0028-0836; EISSN : $1476-4687$

[12] S. Neelakantan, "In India, plagiarism is on the rise," GlobalPost, pp. 142-143, October, 18th, 2009.

[13] A. J. Smith, "The task of the referee," IEEE Computer, vol. 23, pp. 65-71, 1990.

[14] [Online]. Available: http://cobweb.ecn.purdue.edu/ vijay/papers/ acceptance.html

[15] [Online]. Available: www.edu.ro/

[16] [Online]. Available: www.fizica.unibuc.ro/fizica/

[17] [Online]. Available: thomsonreuters.com/products_services/science/free/ essays/impact_factor/

[18] [Online]. Available: www.hefce.ac.uk/pubs/hefce/2009/09_39/

[19] A. Wilcox, "Rise and fall of the Thomson impact factor," Epidemiology, vol. 19, pp. 373-374, 2008, ISSN: 1044-3983. Online ISSN: 1531-5487. 